Fourth International Conference on Sustainable Construction Materials and Technologies http://www.claisse.info/Proceedings.htm

SCMT4

Las Vegas, USA, August 7-11, 2016

\title{
Evaluation of Carbonation Resistivity of Blast Furnace Slag Concrete in Case Curing Differ
}

\author{
Naoko Tsuchiya ${ }^{1 \mathrm{a}}$, Tadatsugu Kage ${ }^{1 \mathrm{~b}}$, and Hiroyuki Tanano ${ }^{1 \mathrm{c}}$ \\ ${ }^{I}$ Material and Components Standards Devision, Building Department, National Institute for Land and \\ Infrastruvture Management, 1 Tachihara Tsukuba Ibaraki, JAPAN ${ }^{l a}$ Email: \\ <tuchiya-n92ta@nilim.co.jp>, ${ }^{1 b}$ Email: <kage-t92ta@nilim.go.jp>, ${ }^{1 c}$ Email: <tanano@kenken.go.jp>.
}

\begin{abstract}
It is need for sustainable and durable buildings to be selected appropriate construction materials. While using blast furnace slag replace for Portland cement could be advantage to reducing $\mathrm{CO}_{2}$ of cement pyroprocess, carbonation resistivity of concrete including blast furnace slag would be poor. Forward durable concrete, curing of the concrete is very important for the density of the surface layer. The aim of this study is to clear how concrete which blast furnace slag much replacing for Portland cement achieve demanded carbonation resistivity. Then, carbonation accelerate experiment was studied. The replacing rate of blast furnace slag for Portland cement are 0, 45 and $70 \%$ and water binder ratio are 45 and $60 \%$. Simulated wall removed formwork at 3, 4, 7, and 10 day are prepared on the 3 kind of temperature conditions $\left(5-10^{\circ} \mathrm{C}, 15-25^{\circ} \mathrm{C}, 28-35^{\circ} \mathrm{C}\right)$, and $\varphi 10 \times 20 \mathrm{~cm}$ cylinder from that were studied by carbonation accelerate experiment. In addition, 28 day water curing specimens are prepared and studied. Addition to carbonation test, 28day strength are tested. From the experiments, it is mentioned that several case of curing temperature and the formwork term caused the carbonation resistivity of the concrete surface down. And the estimation of carbonation resistivity by standard curing specimen could cause error estimation. While, those cases could have a relationship with the strength rate for standard specimen.
\end{abstract}

\section{INTRODUCTION}

Toward sustainable society, it is advantaged to use reinforced concrete constructions long lasted, for using long lead a lowering in amount of $\mathrm{CO}_{2}$ and virgin materials. [Koji Sakai, and Takafumi Noguchi, 2012]

Carbonation of concrete is one of most popular degradation and resistibility of that need to be preliminary evaluated for safety use of concrete structures in-service period.

Concrete carbonation process is presented as diffusion phenomenon. [A. M. Neville, 2004] Therefore, a stated $\mathrm{pH}$ depth can be expressed as condensed formula (1) on the some condition that the concrete is homogeneous under steady humidity.

$\mathrm{D}=\mathrm{A} \sqrt{\mathrm{t}}$

D : depth

A: coefficient of carbonation rate 
However, actual concrete components in city could be consisted of less dense surface layer and more dense part inside. In case concrete is not homogeneous, carbonation process could not be applied formula (1), and it need to be cared for time range. Such a diverse dense of concrete component are caused by some factor as materials chemical components, mix proportion, curing time, curing temperature and component size. [Architectural Institute of Japan, 2001] Using much slag develop concrete intensity up more slowly than normal cement, while it is advantaged at $\mathrm{CO}_{2}$ lowering. So, it is need to know haw high mixed slag concrete component are cured make concrete surface density. Also, we need take care when concrete carbonation resistibility is evaluated by formula (1).

Then, the object of this research is studying about carbonation resistibility of concrete surface. Study was carried by comparing the coefficients of carbonation rate, which were taken from day term cured wall specimens and standard one, at any carbonation acceleration time.

\section{EXPERIMENTAL INVESTIGATION}

Mixture proportions. The replacing rates of blast furnace slag for Portland cement are 0, 45 and 70\%, and water binder ratios are 47 and $60 \%$.

\section{Casting, Curing, and Sealing}

(1) Simulated wall specimen. $1200 \times 1000 \times 200$ Simulated wall were made at the 3 kind of temperature conditions $\left(5-10^{\circ} \mathrm{C}, 15-25^{\circ} \mathrm{C}, 28-35^{\circ} \mathrm{C}\right)$.

Formworks of those were removed at 2,7 , and 14 day, and $\varphi 10 \times 20 \mathrm{~cm}$ cylinder were taken from simulated wall at 56 day age, and then those cylinder were cured in $20^{\circ} \mathrm{CRH} 60 \%$ atmosphere for over 28 days. After curing, the curved surfaces of these were sealed by epoxy resin.

(2) Standard specimen. $100 \times 100 \times 400$ prism were casted, demolded at 2 day, and were cured in $20^{\circ} \mathrm{C}$ water by 28 day age. After that, those were cured in $20^{\circ} \mathrm{CRH} 60 \%$ atmosphere. Then, 4 faces were sealed not involving carbonation exposure faces.

Specimens. Table.1 shows prepared specimens settled above.

Table 1. Prepared specimens

\begin{tabular}{|c|c|c|c|c|c|}
\hline specimen & \multicolumn{3}{|c|}{ Simulated wall } & $\begin{array}{l}\text { cylinder taken from } \\
\text { Simulated wall }\end{array}$ & Standard \\
\hline figure & \multicolumn{3}{|c|}{$1200 \times 1000 \times 200 \mathrm{~mm}$ Simulated wall } & $\begin{array}{l}\varphi 100 \times 200 \quad \mathrm{~mm} \\
\text { cylinder }\end{array}$ & $\begin{array}{l}100 \times 100 \times 400 \\
\text { mm prism }\end{array}$ \\
\hline $\mathrm{W} / \mathrm{B}$ & \multicolumn{5}{|l|}{$47,60 \%$} \\
\hline Slag Rate & \multicolumn{5}{|l|}{$0,45,70 \%$} \\
\hline \multirow[t]{2}{*}{ Curing temp. } & \multirow[t]{2}{*}{$5-10^{\circ} \mathrm{C}$} & \multirow[t]{2}{*}{$15-25^{\circ} \mathrm{C}$} & \multirow[t]{2}{*}{$28-35^{\circ} \mathrm{C}$} & $\begin{array}{l}\text { follow the left temp.by } \\
56 \text { day age }\end{array}$ & \multirow[t]{2}{*}{$20^{\circ} \mathrm{CRH} 60 \%$} \\
\hline & & & & $20^{\circ} \mathrm{C}$ from 56 day age & \\
\hline Formwork & $4,7,14$ day & 2,7 day & 2,7 day & - & $\begin{array}{l}\text { In water by } \\
\text { 28day age }\end{array}$ \\
\hline
\end{tabular}

Carbonation Accelerate Experiment. Both $\varphi 10 \times 20 \mathrm{~cm}$ cylinder from simulated walls and 28 day water curing specimens were studied by accelerated carbonation test. Accelerate facility was set as $20^{\circ} \mathrm{C}$, RH60\%, and $\mathrm{CO}_{2} 5 \%$. Accelerate time were 4, 8, 13 and 26weeks. And carbonation depth of concrete were measured by JIS A 1152 Method for measuring carbonation depth of concrete. 
Strength Test. $\varphi 10 \times 20 \mathrm{~cm}$ cylinder from simulated walls at 28 day age and 28 day water curing specimens were tested strength by JIS A 1108 Method of test for compressive strength of concrete.

\section{RESULTS AND DISCUSSIONS}

Accelerate Carbonation Depth at Each Accelerate Age. Figure 1, figure 2 and figure 3 shows the results of accelerate carbonation depth at each accelerate age, distinctly curing temperature.

In explanatory note, $\mathrm{N}, \mathrm{BB}$ and $\mathrm{BC}$ means the replacing rates, 0,45 and $70 \%$ of blast furnace slag for Portland cement. And 47 or 60 means water binder ratio.2day, 7 day etc. means the term of formwork.

From figure 1, there are no remarkable large difference in (a), (b) and (c). Also the results of 2day, 7day and std. are about same. Similarly, from the figure 2, there are no remarkable large difference. So, N47 and $\mathrm{BC} 47$ simulated wall concrete are not caused by curing temperature and the formwork term. Meanwhile, from figure 3 (b) and (C), there are difference between each formwork days and the standard specimen. Remarkably, figure 3 (C) shows that the results are not same each formwork day. These result mean the curing temperature and the formwork term caused the carbonation resistivity of the concrete surface weak.

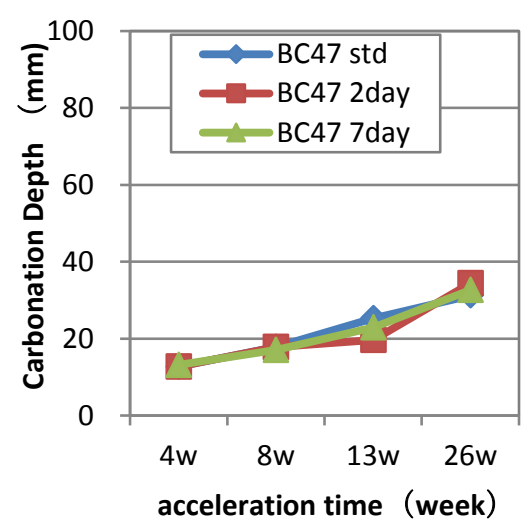

(a) $28-35^{\circ} \mathrm{C}$

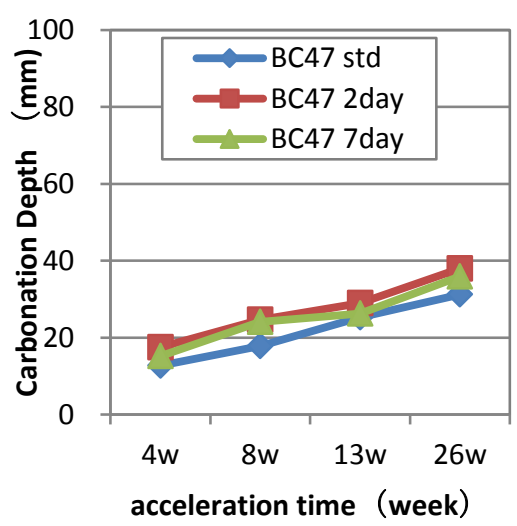

(b) $15-25^{\circ} \mathrm{C}$

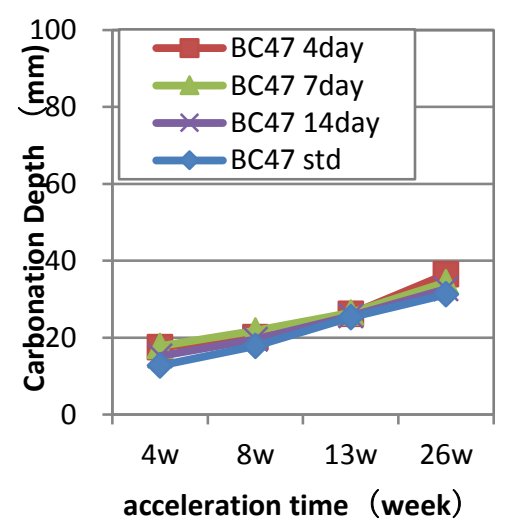

(c) $5-10^{\circ} \mathrm{C}$

Figure 1. Accelerate Carbonation Depth at each Accelerate Age (BC47).

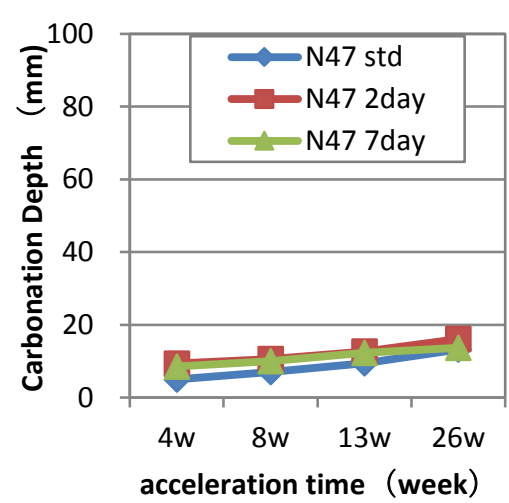

(a) $28-35^{\circ} \mathrm{C}$

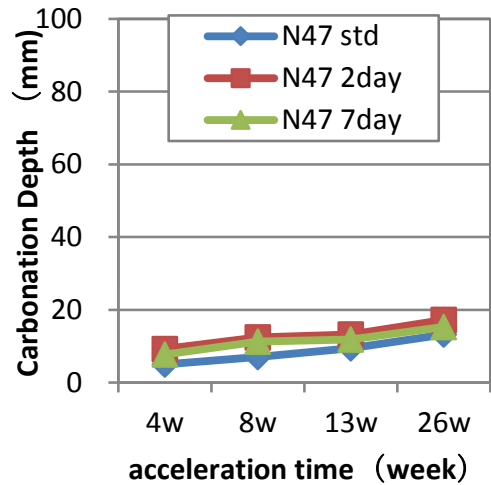

(b) $15-25^{\circ} \mathrm{C}$

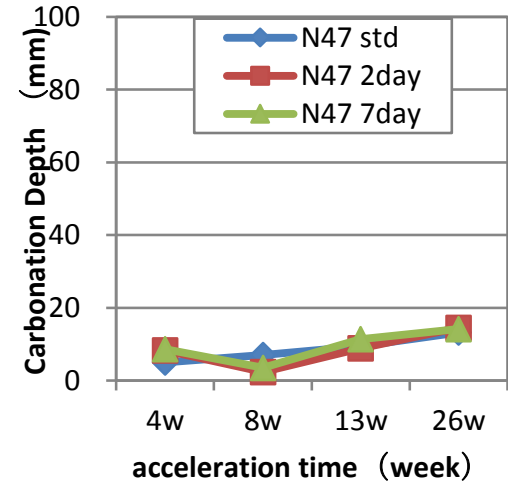

(c) $5-10^{\circ} \mathrm{C}$

Figure 2. Accelerate Carbonation Depth at each Accelerate Age (N47) 


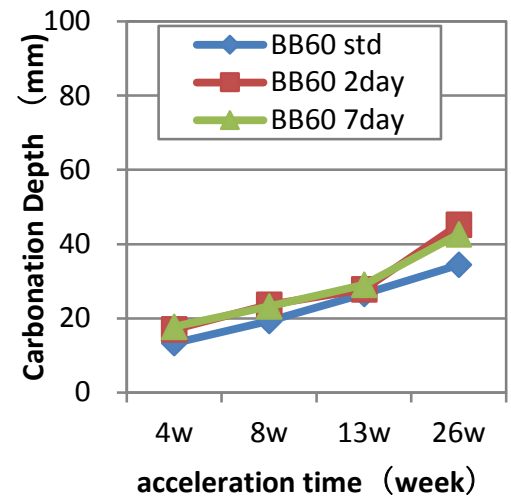

(a) $28-35^{\circ} \mathrm{C}$

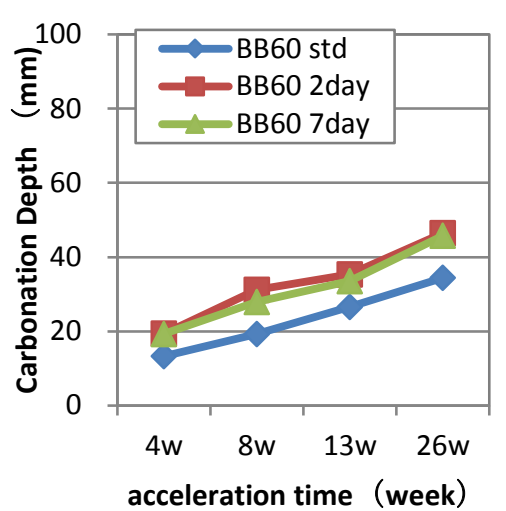

(b) $15-25^{\circ} \mathrm{C}$

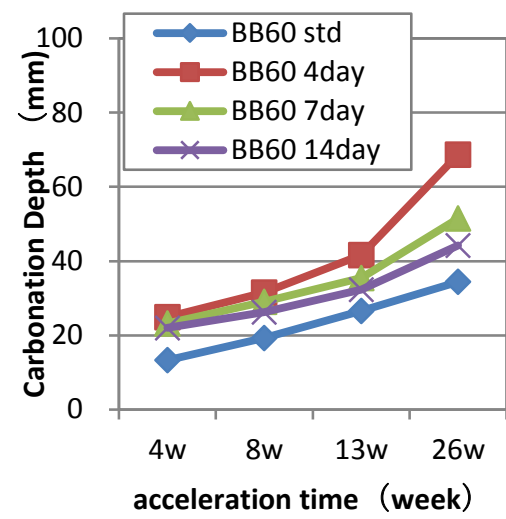

(c) $5-10^{\circ} \mathrm{C}$

Figure 3. Accelerate Carbonation Depth at each Accelerate Age (BB60)

Coefficient of Carbonation Rate of Each Accelerate Age. Figure 4, figure 5 and figure 6 shows the coefficient of carbonation rate at each accelerate age, distinctly curing temperature.

As far as standard specimen, the coefficient of carbonation rate A in either time are mostly same in same mix. From figure 4 (b) and (c), the relationships of the coefficient $A$ and acceleration time show diagonally right down. Therefore, there are difference in corbonation resistivity between day term curing specimens and standard specimens at 4week and 8week. Add to that, the coefficient A of day term curing are larger than standard. From figure 1, carbonation depth shows $20 \mathrm{~mm}$ at 8 weeks. Those means that estimation of carbonation resistivity of $20 \mathrm{~mm}$ depth surface part by standard curing specimen cause error estimation. In a similar way, figure 5 shows the difference in the coefficient A between day term curing and standard at 4 week and 8 week, and figure 2 shows the carbonation depth are $10 \mathrm{~mm}$ at 8 weeks. Then, from figure 6, the coefficient $A$ of day term curing are larger than standard one in any acceleration time. That means the estimation of carbonation resistivity of BB60 by standard curing specimen cause error estimation. Also the results shows that, removed formworks more early, the coefficients of carbonation rate are larger.

From these results, it is mentioned that curing temperature and formwork term cause the carbonation resistivity of concrete or concrete surface down. On another front, it is known that the cover depth of rebar have about $5 \mathrm{~mm}$ standard deviation by the construction error in Japan. [Hitoshi Hamasaki, 2013] So, it could be inadequacy that the carbonation resistivity is estimated with no change by standard curing specimen

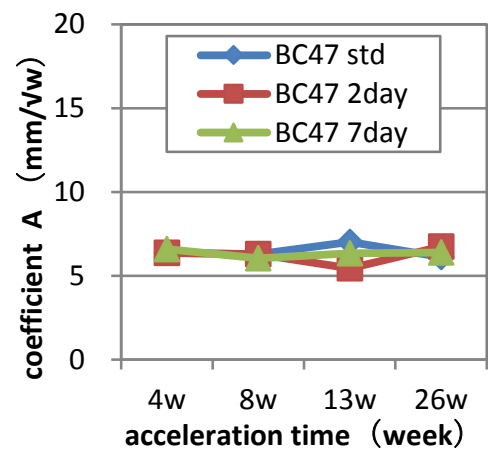

(a) $28-35^{\circ} \mathrm{C}$

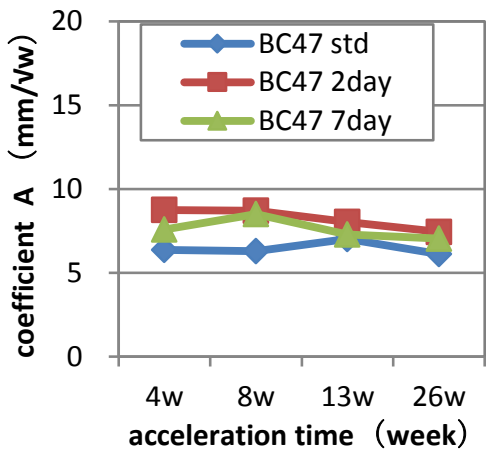

(b) $15-25^{\circ} \mathrm{C}$

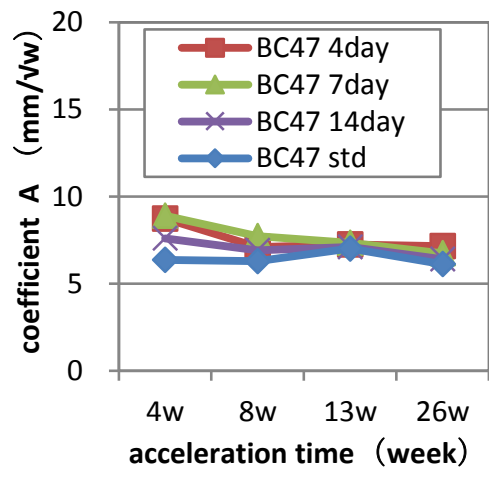

(c) $5-10^{\circ} \mathrm{C}$

Figure 4. Coefficient of Carbonation Rate of each Accelerate Age (BC47) 


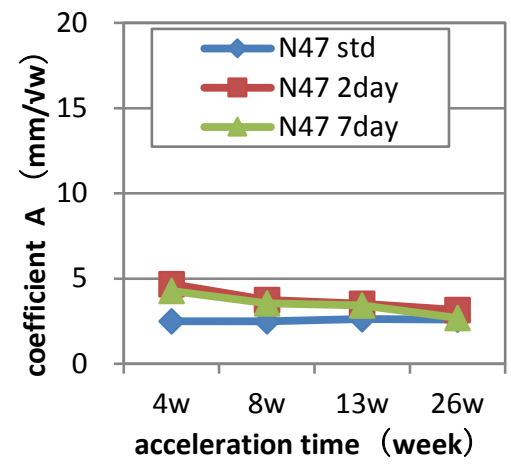

(a) $28-35^{\circ} \mathrm{C}$

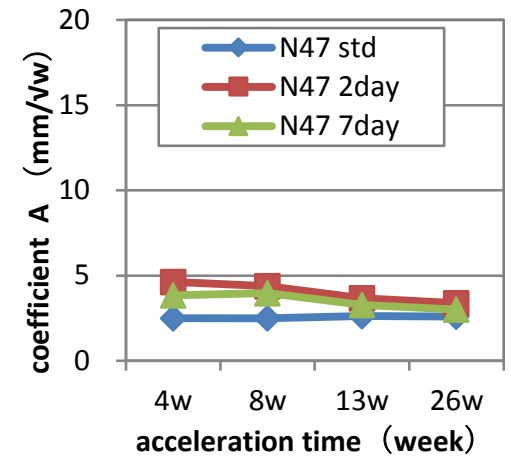

(b) $15-25^{\circ} \mathrm{C}$

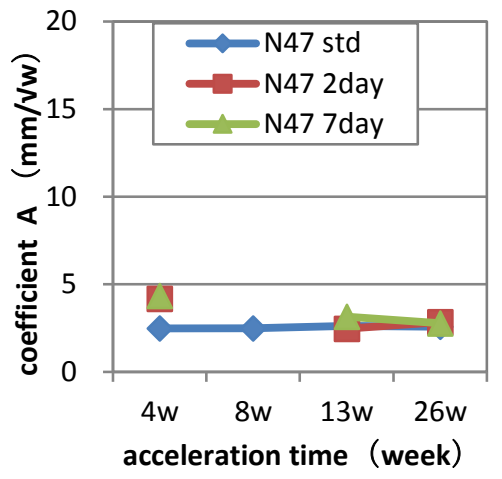

(c) $5-10^{\circ} \mathrm{C}$

Figure 5. Coefficient of Carbonation Rate of each Accelerate Age (N47)

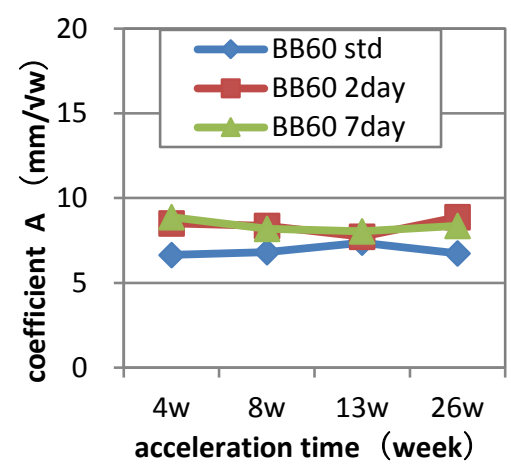

(a) $28-35^{\circ} \mathrm{C}$

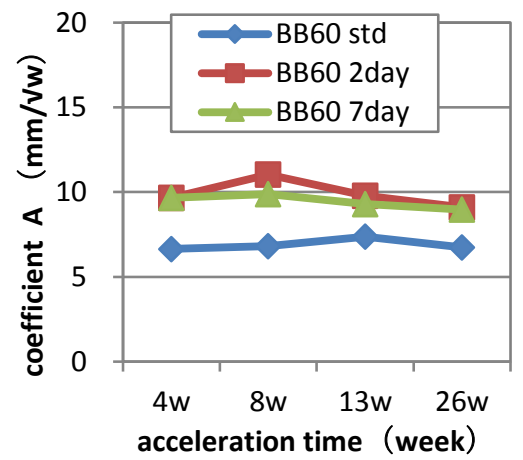

(b) $15-25^{\circ} \mathrm{C}$

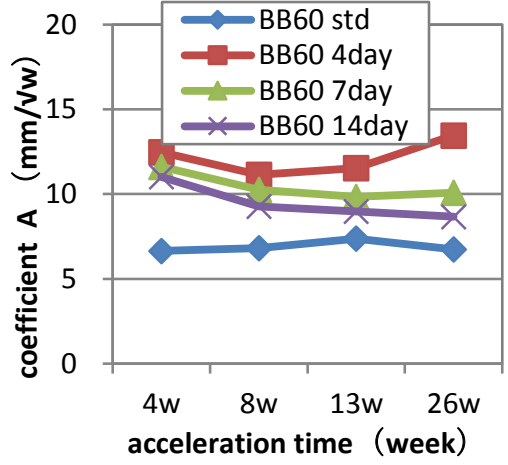

(c) $5-10^{\circ} \mathrm{C}$

Figure 6. Coefficient of Carbonation Rate of each Accelerate Age (BB60)

Strength result. Table. 2 shows 28 day strength results. Also, strength rate for standard specimens are showed. Add to that, what is confirmed remarkably difference in carbonation rate between wall specimens and standard one from above Figures results are noted as $\odot$. In case carbonation rate have a difference between wall specimens and standard one, the strength rate for standard specimen is predisposed to be small. Also, it is a kind of mentioned that if the strength rate for standard one is less than 0.80 , the concrete surface has lower carbonation resistivity than standard specimen does.

\section{CONCLUSION}

The following conclusions can be drawn from the study provided in the paper:

- Several case of curing temperature and the formwork term caused the carbonation resistivity of the concrete surface down.

- As far as JIS standard curing specimen, the coefficients of carbonation rate in either acceleration time $(4,8,13$ and 26 week) are mostly same in same mix.

- In several mix and curing cases, the coefficients of carbonation rate of day term curing are larger than standard one.

- From the above, the estimation of carbonation resistivity by standard curing specimen could cause error estimation. 
- It is a kind of mentioned that if the strength rate for standard one is less than 0.80 , the concrete surface has lower carbonation resistivity than standard specimen does. So the case that the concrete surface have a lower carbonation resistivity could have a relationship with the strength rate for standard specimen

Table 2. 28day strength results

\begin{tabular}{|l|l|l|l|l|l|l|}
\hline Temp. & Mix & Specimen & $\begin{array}{l}\text { Formwork } \\
\text { term } \\
\text { (day) }\end{array}$ & $\begin{array}{l}\text { Strength } \\
\left(\mathrm{N} / \mathrm{mm}^{2}\right)\end{array}$ & $\begin{array}{l}\text { Strength rate } \\
\text { for } \\
\text { strength }\end{array}$ & $\begin{array}{l}\text { *carbonation } \\
\text { difference } \\
\text { for std. }\end{array}$ \\
\hline $20^{\circ} \mathrm{C}$ & BB60 & Std. & - & 26.5 & - & - \\
\hline $20^{\circ} \mathrm{C}$ & BC47 & Std. & - & 35.0 & - & - \\
\hline $20^{\circ} \mathrm{C}$ & N47 & Std. & - & 37.3 & - & - \\
\hline $28-35^{\circ} \mathrm{C}$ & BB60 & simulated wall & 2 & 24.2 & 0.91 & \\
\hline $28-35^{\circ} \mathrm{C}$ & BB60 & simulated wall & 7 & 24.4 & 0.92 & \\
\hline $15-25^{\circ} \mathrm{C}$ & BB60 & simulated wall & 2 & 21.5 & 0.81 & $\circ$ \\
\hline $15-25^{\circ} \mathrm{C}$ & BB60 & simulated wall & 7 & 23.0 & 0.87 & $\circ$ \\
\hline $5-10^{\circ} \mathrm{C}$ & BB60 & simulated wall & 4 & 17.6 & 0.66 & $\circ$ \\
\hline $5-10^{\circ} \mathrm{C}$ & BB60 & simulated wall & 7 & 17.3 & 0.65 & $\circ$ \\
\hline $5-10^{\circ} \mathrm{C}$ & BB60 & simulated wall & 14 & 20.4 & 0.77 & $\circ$ \\
\hline $28-35^{\circ} \mathrm{C}$ & BC47 & simulated wall & 2 & 32.9 & 0.94 & \\
\hline $28-35^{\circ} \mathrm{C}$ & BC47 & simulated wall & 7 & 31.8 & 0.91 & \\
\hline $15-25^{\circ} \mathrm{C}$ & BC47 & simulated wall & 2 & 30.6 & 0.87 & \\
\hline $15-25^{\circ} \mathrm{C}$ & BC47 & simulated wall & 7 & 32.2 & 0.92 & \\
\hline $5-10^{\circ} \mathrm{C}$ & BC47 & simulated wall & 4 & 29.1 & 0.83 & \\
\hline $5-10^{\circ} \mathrm{C}$ & BC47 & simulated wall & 7 & 30.1 & 0.86 & \\
\hline $5-10^{\circ} \mathrm{C}$ & BC47 & simulated wall & 14 & 31.5 & 0.90 & \\
\hline $28-35^{\circ} \mathrm{C}$ & $\mathrm{N} 47$ & simulated wall & 2 & 42.0 & 1.13 & \\
\hline $28-35^{\circ} \mathrm{C}$ & $\mathrm{N} 47$ & simulated wall & 7 & 39.1 & 1.05 & \\
\hline $15-25^{\circ} \mathrm{C}$ & $\mathrm{N} 47$ & simulated wall & 2 & 35.9 & 0.96 & \\
\hline $15-25^{\circ} \mathrm{C}$ & $\mathrm{N} 47$ & simulated wall & 7 & 37.0 & 0.99 & \\
\hline $5-10^{\circ} \mathrm{C}$ & $\mathrm{N} 47$ & simulated wall & 2 & 47.7 & 1.28 & \\
\hline $5-10^{\circ} \mathrm{C}$ & $\mathrm{N} 47$ & simulated wall & 7 & 45.3 & \\
\hline
\end{tabular}

*what is confirmed difference between carbonation rate and std. one remarkably

\section{ACKNOWLEDGEMENTS}

Support for this research project was provided by the promotion project of consolidating building standards. Dr. Masuda belong to Nihon University was the Project Manager for the project. All member of the project are acknowledged. Especially, students belong to Nakata lab. Nihon University and Ootsuka lab. Institute of Technologists carried out experiments in large part. The students are gratefully acknowledged. 


\section{REFERENCES}

A. M. Neville, Properties of concrete, 2004.

Architectural Institute of Japan, Recommendation for practice of concrete with Portland cement and ground granulated blast-furnace slag, 2001.

Architectural Institute of Japan, Recommendation for practice of concrete with Portland blast-furnace slag cement, 2001.

Koji Sakai, and Takafumi Noguchi, The sustainable use of concrete, 2012.

Hitoshi Hamasaki, Study on securing of cover depth of reinforced concrete buildings, Report of the building research institute, No.13, 2013. 